\title{
Comparison of a central location test versus a home usage test for consumer perception of ready-to-mix protein beverages
}

\author{
M. T. Zhang, ${ }^{1}$ Y. Jo, ${ }^{1}$ K. Lopetcharat, ${ }^{2}$ and M. A. Drake ${ }^{1 *}$ (1) \\ ${ }^{1}$ Department of Food, Bioprocessing and Nutrition Sciences, Southeast Dairy Foods Research Center, North Carolina State University, \\ Raleigh 27695 \\ ${ }^{2}$ Nouveau Centric Co. Ltd., Bangkok 10250, Thailand
}

\section{ABSTRACT}

Ready-to-mix (RTM) whey protein beverages are an expanding product category, and sensory properties strongly affect consumer acceptance and purchase intent. Because consumers themselves prepare RTM whey protein beverages, understanding possible gaps between central location test (CLT) and home usage test (HUT) results is critical. The objectives of this study were to compare results obtained from a CLT and a HUT and to identify the drivers of liking and disliking vanilla-flavored RTM whey protein beverages. Fourteen commercial vanilla-flavored RTM whey protein beverages were rehydrated with spring water at $15 \%$ solids (wt/vol) and evaluated by a trained panel $(\mathrm{n}=8)$. Ten representative products were selected for consumer testing. Rehydrated beverages were subsequently evaluated by protein beverage consumers (n $=160$ ) in a CLT. Nine representative products were selected for the HUT. Consumers prepared and evaluated individual beverages over 3 consecutive weeks, trying 3 samples each week. Overall liking and other attributes were scored by consumers in both tests. Data were evaluated by univariate and multivariate statistical analyses. Overall liking scores from the HUT were higher than scores from the CLT. The products with the highest and lowest overall liking scores were consistent between the CLT and HUT. More differences were observed among beverages by CLT compared with HUT when liking was averaged across all consumers. Both methods identified 2 distinct consumer clusters. Fruity flavor and sweet taste were drivers of liking, whereas cardboard flavor and bitter taste were drivers of disliking in both methods. The HUT exclusively identified thickness (viscosity) as a driver of liking and astringency as a driver of disliking. These results sug-

Received July 13, 2019.

Accepted December 6, 2019.

*Corresponding author: mdrake@ncsu.edu gest that a CLT can be used to differentiate consumer acceptance among vanilla-flavored RTM whey protein beverages. A HUT should be used to provide more intensive insights for mouthfeel and mixing experiencerelated attributes.

Key words: central location test, home usage test, flavor, mouthfeel

\section{INTRODUCTION}

Consumers in the United States are increasing the protein content in their diet, which makes whey protein beverages an expanding product category (Gerdes, 2012; Jacobson, 2015). The ingredients of whey protein beverages, $80 \%$ whey protein concentrate and whey protein isolate, are complete sources of the $9 \mathrm{EAA}$ and also contain high amounts of branched-chain AA, which support muscle recovery after exercise (Blomstrand and Saltin, 2001; Hazen, 2003). In additional to basic nutritional benefits, whey proteins can support antimicrobial and antiviral actions, immune system stimulation, antioxidant ability, anticarcinogenic activity, and other metabolic features (Madureira et al., 2007; Ha and Zemel, 2003; Solak and Akin, 2012). Although whey protein beverages have multiple special health benefits and functionalities, nutrition and health claims cannot drive consumer liking if a protein beverage does not have a desirable taste (Gruenwald, 2009; Oltman et al., 2015; Harwood and Drake, 2019). Thus, it is important for food product manufacturers to understand consumer acceptance of whey protein beverages.

Protein beverages fall into 2 basic categories: readyto-drink (RTD) and ready-to-mix (RTM). Ready-todrink beverages are sold in containers, and consumers can directly drink them. Ready-to-mix beverages are sold in powder form and must be rehydrated by consumers, who can choose the liquid base and mixing method. Therefore, for RTM beverages, in addition to flavor and texture (mouthfeel), the mixing experience is also part of the whole consumer usage experience. Whey protein ingredients can impart undesirable fla- 
vors, including cardboard, brothy, metallic, cucumber and soapy flavors; bitter taste; and astringency (Carunchia Whetstine et al., 2005; Russell et al., 2006; Wright et al., 2009). Many of these flavors can carry over into protein beverages (Beecher et al., 2006; Wright et al., 2009; Oltman et al., 2015).

Some previous work has addressed consumer acceptance of whey protein beverages. Wright et al. (2009), Evans et al. (2010), and Oltman et al. (2015) demonstrated that protein-specific off-flavors in whey protein beverages negatively affected consumer acceptance. A study conducted by Childs and Drake (2010) investigated the impact of astringency and protein-specific off-flavors on consumer acceptance of clear acidic whey protein beverages. In addition, Oltman et al. (2015) reported that nutritional priming statements did not significantly affect consumer liking of protein beverages if the samples contained undesirable flavor. All of these studies evaluated RTD beverages. Studies have not addressed sensory properties of RTM beverages. More recently, Parker et al. (2018) investigated the role of nonnutritive sweeteners and sweetener blends on the sensory properties of vanilla RTM whey protein beverages. Drivers of liking were not evaluated.

Identification of drivers of liking is useful for understanding specific attributes of products that are appealing to consumers. Additionally, because different groups of consumers might have different preferences for products and different drivers of liking, it is useful to discover the key drivers of liking among consumer groups and to identify relationships between attributes, product characteristics, and consumer clusters. This process is traditionally done by external preference mapping, a process that identifies relationships between objective descriptive analysis data with subjective consumer liking scores. Descriptive analysis with a trained panel is conducted following consumer acceptance testing. Consumer liking data are usually obtained through a central location test (CLT). Several studies have applied this approach for dairy foods (Thompson et al., 2004; Young et al., 2004; Desai et al., 2013; Shepard et al., 2013).

A home usage test (HUT) is the other quantitative consumer testing format. A CLT is usually conducted under standardized and controlled conditions, so that quantitative results are obtained at a relatively lower cost. In contrast, for a HUT, consumers evaluate samples in a home usage setting during or after the preparation that they would typically do. The HUT is less controlled, but it may permit evaluating attributes under conditions that more closely relate to real-life usage. Previous studies with other foods have determined that a CLT format generally obtains more critical and discriminating results from consumers than a HUT (Boutrolle et al., 2005; Boutrolle et al., 2007; Sosa et al., 2008; Sveinsdóttir et al., 2010). Previous studies have also determined that the results of a CLT compared with a HUT were product specific. De Graaf et al. (2005) and Boutrolle et al. (2005) suggested that for products that are strongly related to specific contexts and serving size, a HUT might be more useful for revealing true consumer acceptance.

The drivers of liking for RTM whey protein beverages have not been documented. In the case of RTM whey protein beverages, the choice of mixing liquid (water or milk) and the mixing procedure may affect consumer liking. In a CLT setting where beverages are prepared for consumers in a standardized manner, these factors cannot be measured. Therefore, comparing the role of CLT and HUT test formats on consumer perception of RTM protein beverages is important. The objectives of this study were to identify drivers of liking for vanillaflavored RTM protein beverages and to compare the differences in consumer perception between a CLT and a HUT with vanilla-flavored RTM whey protein beverages.

\section{MATERIALS AND METHODS}

\section{Experimental Overview}

All sensory testing was conducted in compliance with the North Carolina State University (NCSU) Institutional Review Board for human subjects regulations. Protein beverage powders were rehydrated at $15 \mathrm{~g}$ per $100 \mathrm{~mL}$ for all sensory testing. This amount was selected because it represented an approximate average solids content recommended across all commercial RTM. All RTM were thus evaluated at a constant solids content, and the number of grams of protein per serving did not differ across the rehydrated RTM $(P>0.05)$. Sensory properties of 14 rehydrated commercial RTM protein beverages were evaluated by descriptive analysis. Following descriptive analysis, a CLT was conducted with 10 representative RTM beverages. Consumers ( $\mathrm{n}=$ 160) evaluated 5 beverages a day across a 2-d period. Subsequently, a HUT was conducted with 9 selected RTM beverages with 122 consumers who met the same demographic criteria as the CLT. The HUT consumers were allowed to choose the mixing method (shaker bottle, blender, or stir) and the liquid base (water or skim milk). Consumers evaluated 3 beverages a week for $3 \mathrm{wk}$, with a 22 -h enforced break between samples.

\section{RTM Whey Protein Powder Beverages}

Commercial vanilla-flavored whey protein RTM powders $(\mathrm{n}=14)$ were purchased to represent a range 
Table 1. Commercial vanilla ready-to-mix protein beverages and sweeteners ${ }^{1}$

\begin{tabular}{|c|c|c|c|}
\hline Beverage & Test type ${ }^{2}$ & Sweetener & $\begin{array}{l}\text { Whey protein } \\
\text { source }^{3}\end{array}$ \\
\hline 741 & & Acesulfame potassium, sucralose & WPI + WPC \\
\hline 403 & CLT & Stevia & WPI \\
\hline 424 & CLT, HUT & Acesulfame potassium, sucralose & WPI + WPC \\
\hline 630 & HUT & Acesulfame potassium, stevia, sucralose & $\mathrm{WPI}+\mathrm{WPC}$ \\
\hline 825 & & Acesulfame potassium, sucralose & WPC \\
\hline 902 & & Cane sugar, monk fruit extract & WPI \\
\hline 016 & CLT, HUT & Monk fruit extract & $\mathrm{WPI}+\mathrm{WPC}$ \\
\hline 661 & CLT, HUT & Acesulfame potassium, sucralose & WPI \\
\hline 523 & CLT, HUT & Acesulfame potassium, sucralose & $\mathrm{WPI}+\mathrm{WPC}$ \\
\hline 718 & CLT, HUT & Acesulfame potassium, sucralose & WPI + WPC \\
\hline 153 & CLT, HUT & Acesulfame potassium, sucralose & $\mathrm{WPI}+\mathrm{WPC}$ \\
\hline 287 & CLT & Stevia, sugar & $\mathrm{WPI}+\mathrm{WPC}$ \\
\hline 886 & CLT, HUT & Fructose, stevia & WPI + WPC \\
\hline 369 & CLT, HUT & Stevia & WPC \\
\hline
\end{tabular}

${ }^{1}$ Sweeteners and whey protein sources were identified from the ingredient label on the commercial packaging. ${ }^{2} \mathrm{CLT}=$ central location test; HUT $=$ home usage test.

${ }^{3} \mathrm{WPI}=$ whey protein isolate; $\mathrm{WPC}=$ whey protein concentrate.

of brands and market shares (Table 1). Samples were purchased in duplicate lots, and they were received at least 6 mo before their expiration date and stored in the dark at $20^{\circ} \mathrm{C}$.

\section{Descriptive Analysis}

Ready-to-mix protein beverages were rehydrated with deionized water at $15 \mathrm{~g} / 100 \mathrm{~mL}$. Each sample was mixed in a $600-\mathrm{mL}$ shaker bottle (Blender Bottle, Lehi, UT). Protein beverages $(50 \mathrm{~mL})$ were poured into lidded 60-mL soufflé cups (Dart Container Corp., Mason, MI) with random 3-digit codes and tempered to $21^{\circ} \mathrm{C}$ for tasting. Each sample was served monadically with deionized water and unsalted crackers.

A trained descriptive sensory panel $(\mathrm{n}=8,2$ men and 6 women, ages 22 to $50 \mathrm{yr}$ ) evaluated flavors and mouthfeel attributes (orthonasal aroma intensity, inmouth flavors: sweet aromatic, fruity, buttery, cardboard, citrus, bitter taste, sweet taste, sour taste, salty taste, metallic mouthfeel, astringency, aftertaste intensity, and viscosity) of the beverages using a 0 - to 15-point universal intensity scale consistent with the Spectrum method (Drake and Civille, 2003; Lawless and Civille, 2013). Each panelist had more than 60 $\mathrm{h}$ of prior experience with the descriptive analysis of flavor and texture of protein beverages. Each beverage was evaluated in triplicate by each panelist. Data were collected using Compusense Cloud (Compusense Inc., Guelph, ON, Canada).

\section{Consumer Acceptance Testing (CLT)}

Ten representative RTM beverages were selected for consumer evaluation based on market share, product mean sensory attributes, and examination of principal component (PC) biplot results from descriptive analysis (Figure 1). A target number of 160 consumers were recruited from the database of more than 11,000 consumers maintained by the NCSU Sensory Service Center (Raleigh, NC). Consumers were recruited with an online screener using SSI Web (version 8.4.8, Sawtooth Software, Orem, UT). The group of recruited consumers was $70 \%$ men and $30 \%$ women with an even age distribution (18-54 yr). Self-reported RTM beverage consumers were people who exercised at least once per week and consumed RTM protein beverages at least 2 times per month. Consumer acceptance testing took place over $2 \mathrm{~d}$. Consumers who participated were compensated with $\$ 35$ gift card to a local store.

Samples were served in the same manner as for descriptive analysis, except that samples were rehydrated with $4^{\circ} \mathrm{C}$ spring water. Consumers were asked to evaluate overall liking as well as flavor and thickness attributes. Sample orders were randomized, balanced, and pre-assigned to each consumer before the test started, and each consumer evaluated 5 beverages each day. Participants signed a consent form followed by a ballot consisting of questions about RTM beverages. Approximately $60 \mathrm{~mL}$ of each rehydrated RTM beverage was served in a lidded 118-mL soufflé cup with a 3-digit blinding code. Data were collected using Compusense Cloud.

Participants were first asked to evaluate the aroma of the sample. The aroma of each sample was rated using a 9 -point hedonic scale, on which $1=$ dislike extremely and 9 = like extremely, followed by just-about-right (JAR) questions about the aroma intensity, which was rated as follows: 1 or $2=$ not strong enough, $3=$ just about right, and 4 or $5=$ too strong. Consumers 

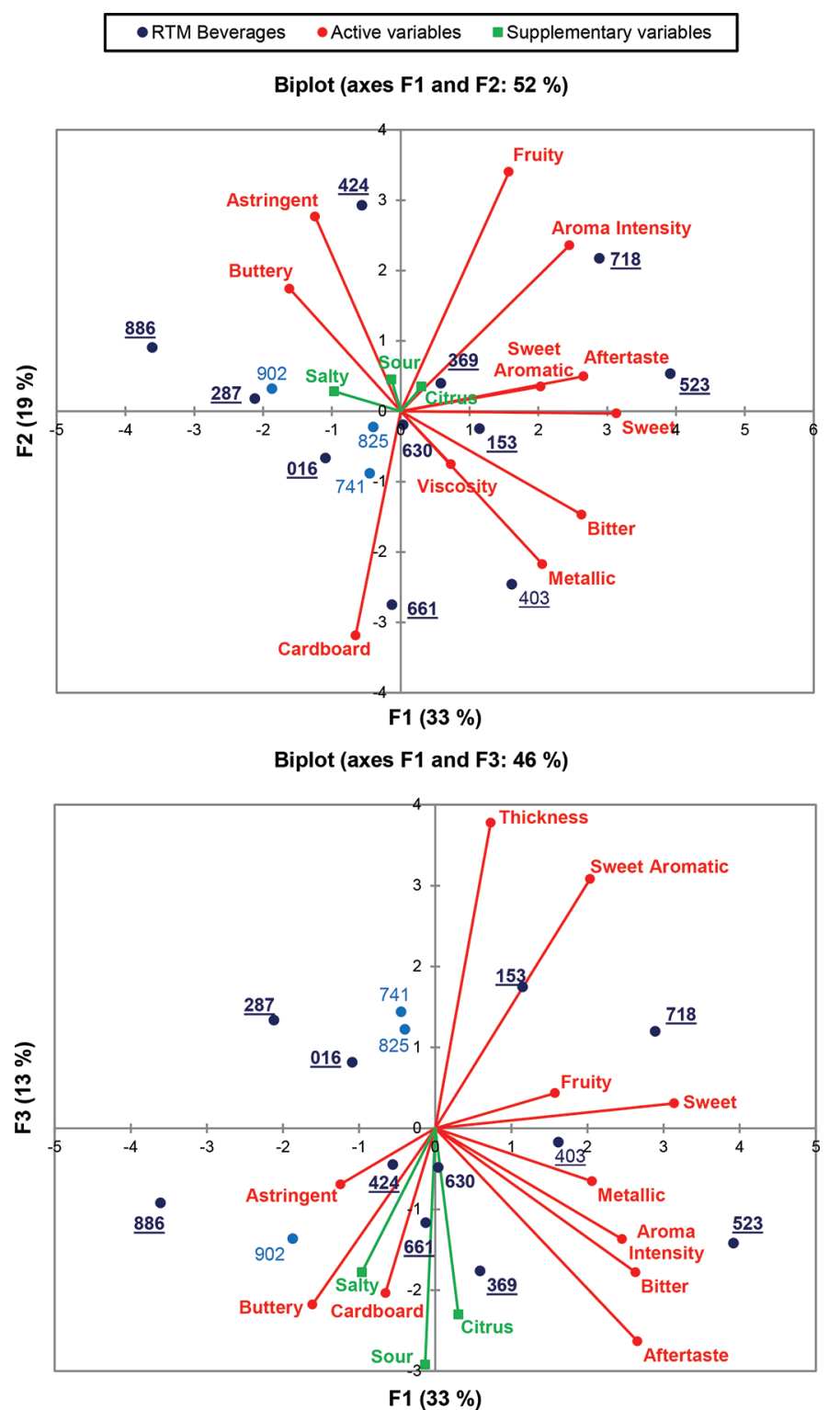

Figure 1. Principal component analysis biplot of trained panel profiles for rehydrated vanilla-flavored ready-to-mix (RTM) protein beverages. Underlined samples were selected for the central location test and bold samples were selected for the home usage test.

were then asked to taste the sample and to evaluate their overall impression using a 9-point hedonic scale. Consumers were also asked to evaluate flavor, sweet taste, dairy/milky flavor, vanilla flavor, thickness, and aftertaste liking using a 9-point hedonic scale. These questions were followed by JAR questions for sweet taste, dairy/milky flavor, vanilla flavor, thickness, and aftertaste. Consumers were instructed to cleanse their palate by rinsing their mouths with deionized water and taking a bite of unsalted cracker during an enforced 4-min rest period between each sample. The longer en- forced rest was to minimize potential carryover from nonnutritive sweeteners, astringency, or both (Parker et al., 2018).

\section{Consumer Acceptance Testing (HUT)}

The HUT was conducted approximately $30 \mathrm{~d}$ after the CLT, and 9 representative samples were selected for the HUT. Eight of these beverages were the 8 most differentiated samples from the CLT results. The ninth beverage had been profiled by descriptive analysis but not included in the CLT. This beverage (630) had moderate intensities of all attributes by descriptive analysis and was not highly distinguished by PC analysis (Figure 1). This beverage was added to the HUT following examination of CLT results based on the need for a moderate-intensity sample.

A target number of 120 consumers was selected. The consumer selection criteria were the same as for the CLT with exceptions for mixing method and liquid base usage. Participants in the HUT did not participate in the CLT. Consumers were asked to choose the liquid base (64 chose to use water, and 58 chose to use skim milk) and mixing method (shaker bottle, blender, or stirring) they usually used for making their own protein beverages. The 9 samples were provided to consumers across 3 continuous weeks in a randomized complete block design. Each consumer received 3 individual packaged samples (35 g of powder sample in each package, enough to make a single $327-\mathrm{mL}$ liquid serving) in a Mylar bag each week. Consumers who participated were compensated with $\$ 50$ gift card to a local store.

For the HUT, $35 \mathrm{~g}$ of each RTM protein beverage was prepackaged in an 118-mL Whirl-Pak bag (ULINE, Pleasant Prairie, WI) and labeled with a random 3-digit code. The 3 prepackaged samples were placed into a 15 $\times 20 \mathrm{~cm}$ metallized zipper-top Mylar bag (ULINE). Consumers came to the Sensory Service Center (Raleigh, NC) each week to pick up their samples. The serving orders of samples were randomized and preassigned to each consumer before the test started, and each consumer was asked to evaluate 3 samples each week. A 22-h enforced rest period elapsed between each sample. Data were collected using Compusense Cloud.

Before making each sample, consumers were asked if they were doing the test after a workout. Participants were then asked to mix the entire bag of each sample with $327 \mathrm{~mL}$ of the liquid they chose when they went through the screener. The consumers then took a photo of the rehydrated beverage and uploaded the photo. Photos were required to ensure that instructions were followed. After the beverage was made, participants answered questions about the ease of the mixing expe- 
rience, appearance, and the aroma liking before they consumed the beverage. A 9-point hedonic scale was used. After consuming the product, consumers provided answers to the same questions asked in the CLT and were also asked to select words to describe the flavor, mouthfeel, and aftertaste of the products using a check-all-that-apply format.

\section{Statistical Analysis}

All statistical analysis was conducted with XLSTAT (version 2016.4; Addinsoft, New York, NY). Descriptive analysis and liking scores were evaluated by ANOVA with Fisher's least significant difference post hoc test. Penalty analysis was conducted to relate JAR scores with overall liking. Percentages of frequencies of JAR responses were calculated using a chi-squared test with a Marascuilo procedure. All 5-point intensity, expectation, and purchase intent data were analyzed by Kruskal-Wallis with Dunn's post hoc nonparametric test. Descriptive analysis data were also analyzed using PC analysis, and attributes that were detected in less than 3 samples were used as supplementary data, which did not contribute to the biplot structure. Consumer cluster segmentation was validated using agglomerative hierarchical clustering first, and then conducted using $\mathrm{k}$ means. Panelists with similar preference patterns were placed into the same cluster. External preference mapping was conducted on factor scores obtained from factor analysis of descriptive analysis means with varimax rotation, and individual consumer liking scores from each cluster using partial least squares regression. All statistical analyses were performed at a $95 \%$ confidence interval.

\section{RESULTS}

\section{Descriptive Analysis}

Fourteen sensory attributes were identified and documented for the selected commercial vanilla-flavored RTM whey protein beverages. The defined sensory lexicon contained orthonasal aroma intensity, 5 aromatics, 4 basic tastes, metallic mouthfeel, aftertaste intensity, astringency, and viscosity attributes (Table 2 and Figure 1). Most of the sensory attributes were adapted from previous studies with whey proteins and whey protein beverages (Carunchia Whetstine et al., 2005; Wright et al., 2009; Oltman et al., 2015). In this study with vanilla-flavored beverages, the vanilla character of the beverages was described as sweet aromatic/vanillin, buttery, fruity, and citrus flavors. All vanilla-flavored protein beverages had varying intensities of the follow- ing attributes: orthonasal aroma intensity, sweet aromatic, cardboard, sweet taste, astringency, aftertaste intensity, and viscosity. Aroma intensity was highest in beverages 523 and 718 . Sweet aromatic flavor was documented to have high intensities in beverages 741 , $825,523,718$, and 153. Fruity flavor was highest in beverages 424 and 718, followed by 523, 825, and 287 . Buttery flavor was highest in beverages 902 and 886, followed by 630,424 , and 718 . Citrus flavor was only detected in beverage 369. Bitter taste was documented in all beverages except 902 . Sour taste was only detected in beverages 902 and 369. Salty taste was exclusive to beverage 902 (Table 2).

Principal component analysis of the trained panel data explained $65 \%$ of the variability on PC 1,2 , and 3 (Figure 1). Principal component $1(33 \%)$ was composed of aroma intensity, sweet aromatic, bitter taste, sweet taste, metallic, and aftertaste intensity, which were all positively loaded on PC 1 . Principal component 2 (19\%) was composed of fruity flavor and astringency, which were positively loaded on PC 2, and cardboard flavor, which was negatively loaded on PC 2. Principal component 3 (13\%) was composed of viscosity, which was positively loaded on PC 3. All beverages were characterized by sweet aromatic and cardboard flavors, sweet taste, astringent mouthfeel, and aftertaste.

Sweet taste was the predominant attribute for all beverages. Sweet aromatic was the predominant aromatic attribute for most of the beverages, except beverage 661. Cardboard flavor was documented in all the beverages and was the predominant aromatic attribute for beverage 661. Cardboard flavor in these beverages is likely due to the whey protein (Beecher et al., 2006; Wright et al., 2009; Oltman et al., 2015). Most beverages were characterized by bitter taste and metallic mouthfeel, and these attributes were likely caused by nonnutritive sweeteners (Schiffman et al., 1995; Guggisberg et al., 2011; Li et al., 2015; Parker et al., 2018). Beverage 403 and 369 were high in bitter taste, and they were the only beverages that used stevia as the sole sweetener (Table 1). Beverage 523 also had high bitterness and had acesulfame potassium and sucralose as the sweetener sources. Beverage 902 was the only beverage that did not have detectable bitterness, and this beverage was partially sweetened with sucrose. Beverages 403, 424, 016, 661, 523, 718, 153, 287, 886, and 369 were selected for the CLT.

\section{Central Location Test}

In the CLT, beverage 153 obtained the highest mean overall liking scores followed by 424,718 , and 886 . Beverages 403 and 369 received the lowest mean overall 


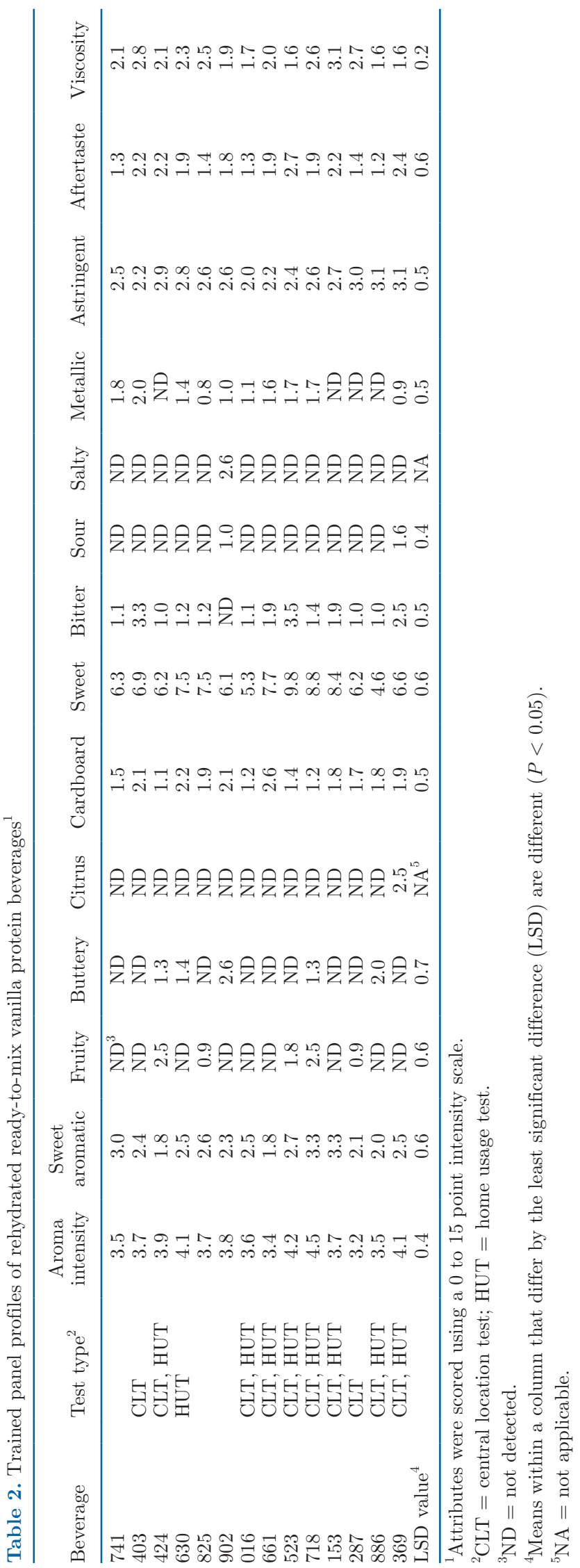

liking scores (Table 3). Moreover, beverage 153, which obtained the highest overall liking score, obtained the highest scores in all the individual attributes, and beverage 403, which obtained the lowest overall liking score, obtained the lowest scores in all the individual attributes (Table 3).

Beverage 153 obtained the highest percentages of JAR in all attributes, and these percentages were at parity with 424, consistent with the high overall liking scores of both of these beverages. Beverage 403 obtained the lowest percentages of JAR in all attributes, and most of the percentages were at parity with 287 and 369 . Beverages 403 and 369 obtained the 2 lowest overall liking scores, and beverage 287 had the third lowest liking (Table 3). Penalty analysis was conducted to relate overall liking to JAR scores (results not shown). For a certain attribute of a product, penalty analysis determines if a deviation from JAR statistically relates to a significant decrease in overall liking (Schraidt, 2009). Except for 153, beverages were penalized for being not strong enough in milky/dairy flavor. All beverages were penalized for being too strong in aftertaste, which was consistent with consumer dislike of bitter and metallic attributes from nonnutritive sweeteners. These results suggest that consumers look for vanilla-flavored protein beverages that have strong dairy/milky flavor and low aftertaste.

Two distinct consumer clusters $(\mathrm{C} 1, \mathrm{n}=88$; $\mathrm{C} 2, \mathrm{n}$ $=72$ ) were identified with differences in overall liking (Figure 2). Overall liking scores across most beverages were higher from $\mathrm{C} 1$ consumers compared with $\mathrm{C} 2$ consumers, except for beverage 424. Consumers from C1 scored the highest overall liking for 523 and scored the lowest overall liking for 403 . However, beverage 523 obtained the third lowest mean overall liking score from $\mathrm{C} 2$ consumers. Consumers from $\mathrm{C} 2$ scored the highest overall liking for 153 and 424 and scored the lowest overall liking for beverage 403, consistent with $\mathrm{C} 1$ consumers. Both consumer groups showed a preference for beverage 153 , followed by 718 . Beverage 424 was only preferred by $\mathrm{C} 2$ consumers. The mean overall liking scores of beverages $016,661,523,718$, and 153 were different $(P<0.05)$ between the 2 consumer clusters, and 523 showed the biggest difference in mean overall liking between these 2 consumer clusters $(P<0.05)$. From external preference mapping, the key drivers of liking for $\mathrm{C} 1$ consumers were fruity flavor and sweet taste (Figure 3). The main driver of dislike was cardboard flavor. For consumers in $\mathrm{C} 2$, the key drivers of liking were fruity and buttery flavors. The drivers of dislike for these consumers were cardboard flavor, bitter taste, metallic mouthfeel, and aftertaste. Fruity flavor was the driver of liking for both clusters, and cardboard flavor was the driver of dislike for both clusters. 


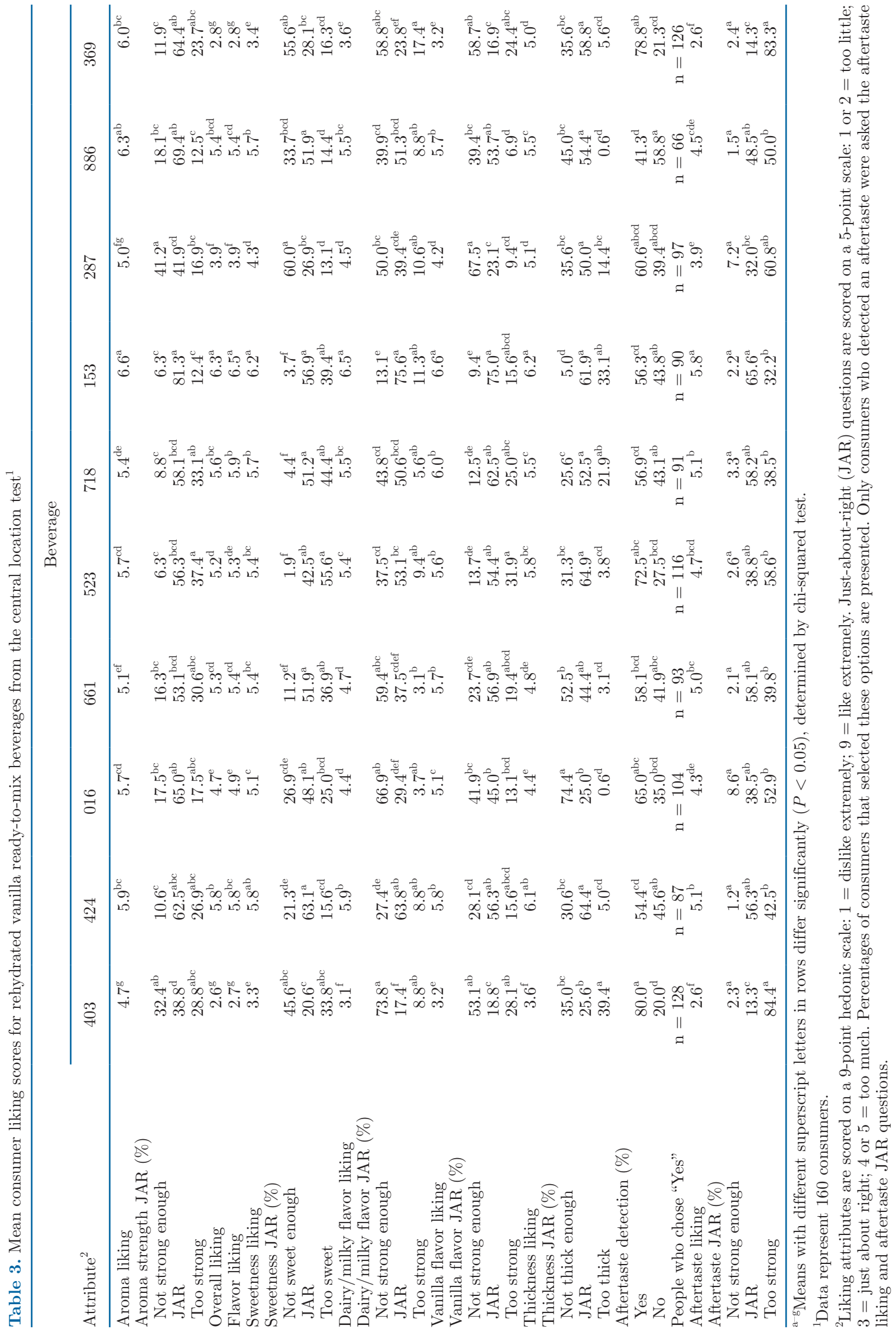


The trained panel results showed that beverage 523 has a moderate level of fruity flavor, the highest intensities of sweet and bitter tastes and aftertaste, and no buttery flavor. The identified drivers of liking and dislike for $\mathrm{C} 1$ and $\mathrm{C} 2$ consumers explained the fact that beverage 523 obtained the highest overall liking from C1 consumers and obtained the third lowest overall liking score from $\mathrm{C} 2$ consumers. These drivers also suggested that for $\mathrm{C} 2$ consumers, the dislike of bitter taste and aftertaste affected acceptance more than the liking of fruity flavor. Consumers from $\mathrm{C} 2$ differed from $\mathrm{C} 1$ by their liking of buttery flavor, and a lack of sweet taste preferences, and the additional dislike of bitter taste, metallic mouthfeel, and aftertaste (Figure 3). Cluster 1 had a higher percentage of men and a lower percentage of women compared with $\mathrm{C} 2(P<0.05 ; 78.4: 21.6$ compared with 55.6:44.4, respectively). No age or exercise frequency or consumption frequency differences were observed between the 2 clusters $(P>0.05$; results not shown). A study of lime drinks conducted by Conner and Booth (1988) concluded that male participants preferred higher sweetness more than female participants. A study of milk products with different sugar and fat levels conducted by Hayes and Duffy (2008) also reported that males preferred milk products that had higher sugar and fat levels. Michon et al. (2009) indicated that female participants tended to give higher perceived intensity scores for sweetness and bitterness.

\section{Home Usage Test}

Beverage 153 obtained the highest mean overall liking score and was at parity with 424 and 523 (Table 4). Beverage 369 received the lowest mean overall liking scores. Moreover, beverage 153, which obtained the highest overall liking score, had the highest scores in all the individual attribute likings, and beverage 369, which obtained the lowest overall liking score, had the lowest scores in all the individual attribute likings (Table 4). For JAR results, beverage 153 obtained the highest percentages of JAR in all attributes, and all these percentages were at parity with most of the other beverages, except 016, 886, and 369. Similar to the CLT, most of the beverages were penalized for not being strong enough in milky/dairy flavor. These scores are consistent with beverages 153 and 424 obtaining the highest overall liking. All beverages were penalized for being too strong in aftertaste. These results, similar to the CLT results, suggest that consumers are looking for vanilla-flavored whey protein beverages that have a light aroma, a dairy/milky flavor, and a low aftertaste. The consumer preferences for dairy/milky flavor and aftertaste were similar between the CLT and the HUT.

For the HUT, 2 distinct consumer clusters $(\mathrm{C} 1, \mathrm{n}$ $=58 ; \mathrm{C} 2, \mathrm{n}=64)$ were identified with differences in overall liking (Figure 4). Overall liking scores across all beverages were generally higher for $\mathrm{C} 1$ consumers com-

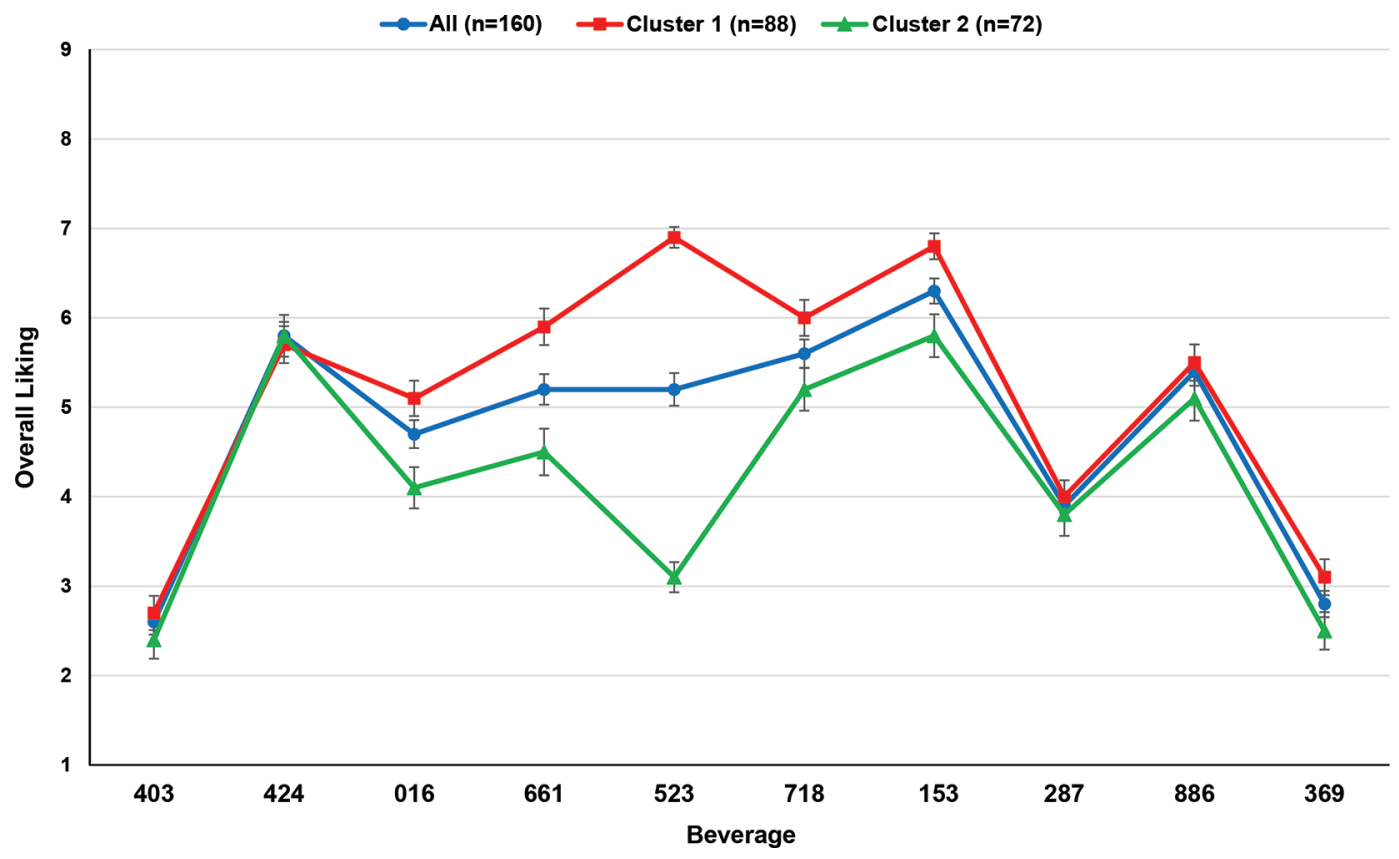

Figure 2. Overall liking scores for rehydrated vanilla-flavored ready-to-mix (RTM) beverages across all consumers and consumer clusters in the central location test. Error bars indicate $95 \%$ confidence intervals. 
A

Correlations on axes $\mathrm{t} 1$ and $\mathrm{t} 2$

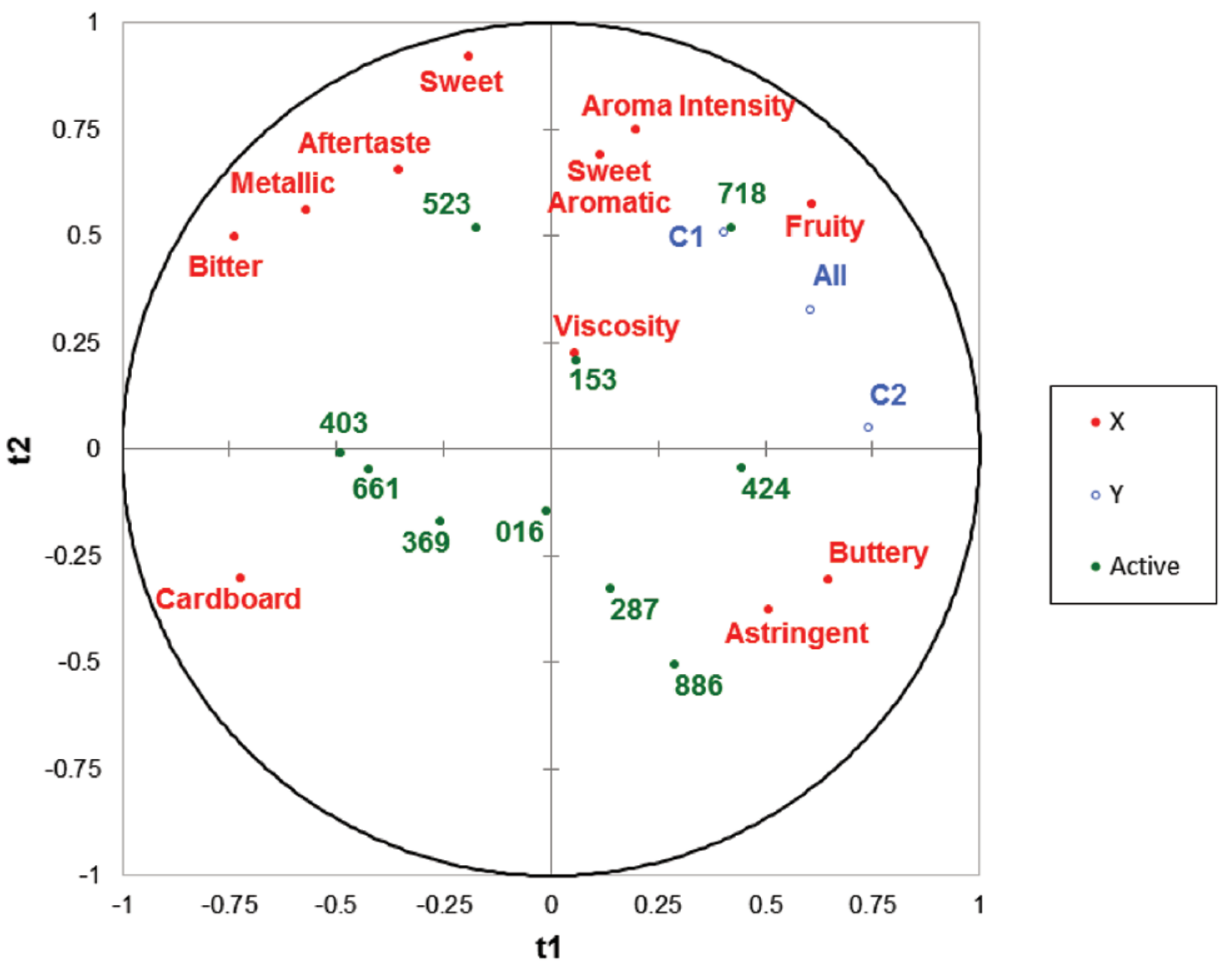

B

Correlations on axes $\mathrm{t} 1$ and $\mathrm{t} 3$

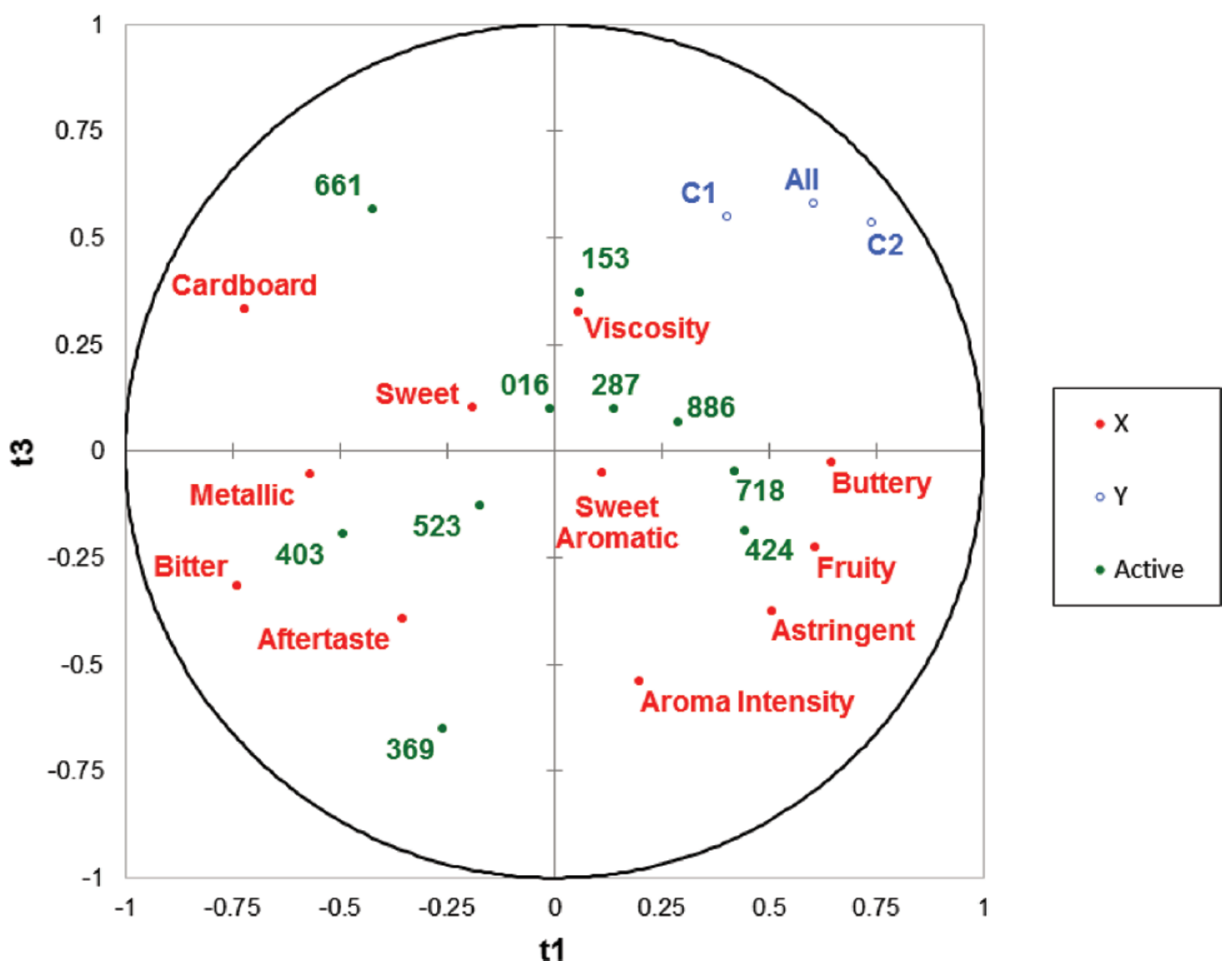

Figure 3. Partial least squares correlation biplot of overall liking scores of clusters $(\mathrm{C} 1=88, \mathrm{C} 2=72)$ for selected rehydrated vanilla-flavored ready-to-mix (RTM) protein beverages in the central location test; trained panel sensory attributes are identified. Numbers represent RTM beverages used for consumer testing. Variance explained as follows: $\mathrm{t} 1=36 \%$; $2=12 \%$; $\mathrm{t} 3=31 \%$. 
Zhang et al.: READY-TO-MIX PROTEIN BEVERAGE TEST COMPARISON

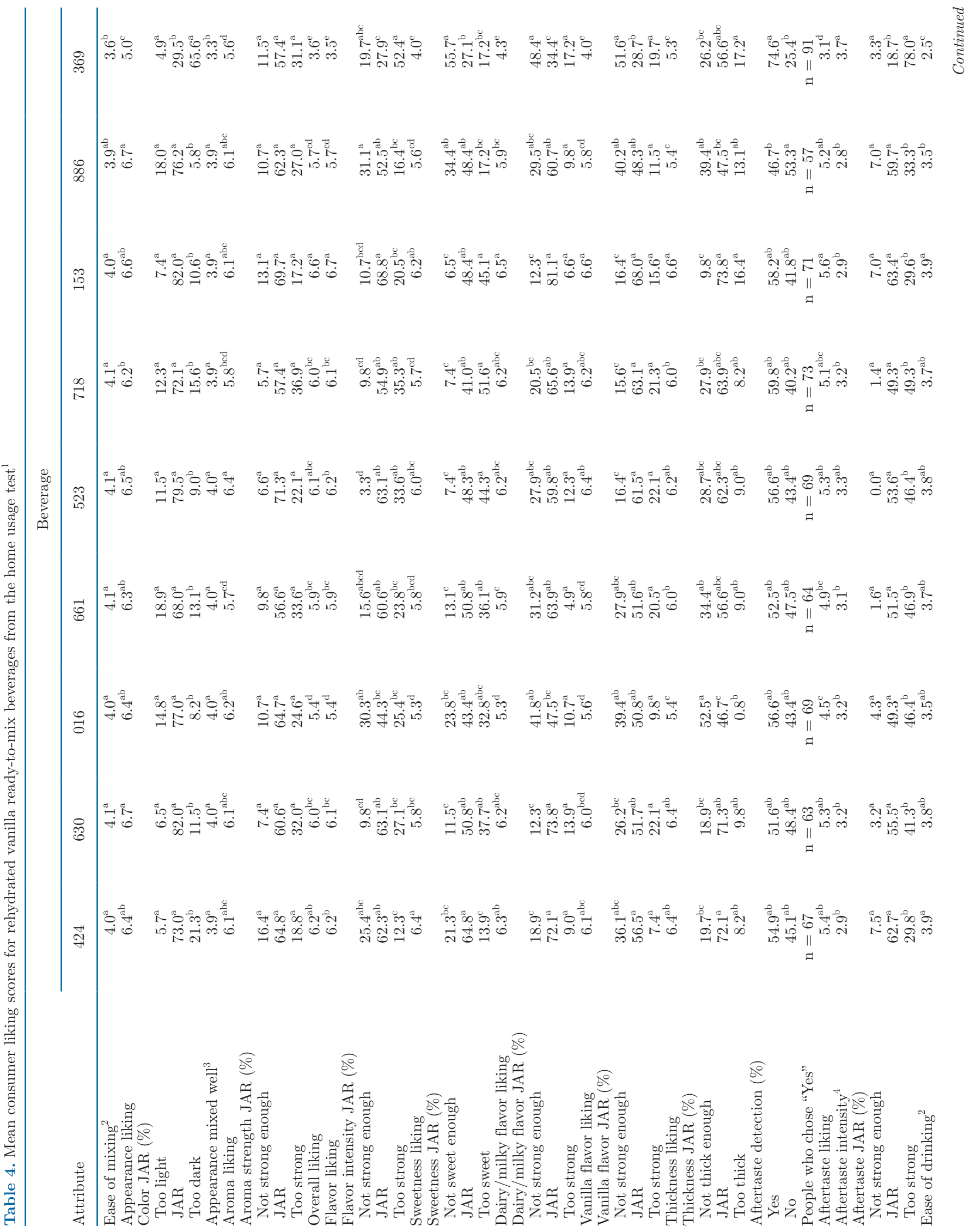




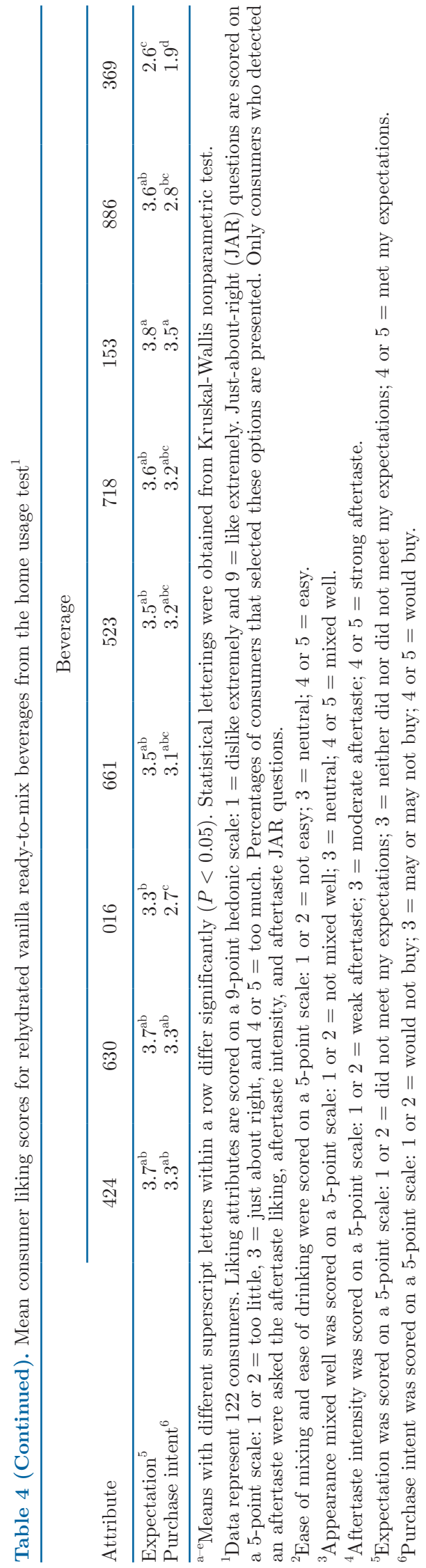

pared with $\mathrm{C} 2$ consumers $(P<0.05)$. Consumers from C1 scored the highest overall liking for 523 and scored the lowest overall liking for 369 . Beverage 523 obtained the third lowest overall liking score from $\mathrm{C} 2$ consumers. Consumers from $\mathrm{C} 2$ scored the highest overall liking for 153 and scored the lowest overall liking for 369, similar to $\mathrm{C} 1$ consumers. Both of these 2 clusters showed preferences for beverage 153. The mean overall liking scores of most of the beverages, except 153, were different between the 2 consumer clusters, and 369 showed the biggest difference in mean overall liking between the 2 clusters $(P<0.05$; Figure 4$)$. For demographic results, in contrast to the results from the CLT, no gender differences were found between clusters $(P>0.05$; results not shown). Cluster 2 contained a greater percentage of consumers ages 45 to 54 yr $(14.1 \%$ in $\mathrm{C} 2$ vs. $1.7 \%$ in $\mathrm{C} 1, P<0.05)$ and also had a higher percentage of individuals that consumed RTM beverages at least once per day ( $35.9 \%$ in $\mathrm{C} 2$ vs. $15.5 \%$ in $\mathrm{C} 1, P<0.05$ ).

The mean overall liking scores from consumers using different liquid bases to make the beverages (water vs. skim milk) were compared. Beverages 016, 661, and 718 obtained higher overall liking scores when skim milk was used $(P<0.05)$, but other beverages were not affected (Table 5). More differences $(P<0.05)$ were observed when beverages were mixed with water compared with skim milk $(P<0.05$, Table 5$)$. A significant interaction was found between choice of base liquid used and overall liking scores $(P<0.05)$. These results indicate that mixing matrix can affect consumer acceptance of RTM products. Water provides the most conservative "worst case scenario" matrix for consumers to evaluate beverages. In contrast, mixing method (stirring vs. shaker bottle vs. blender) and consumption time (consumed after a workout vs. not consumed after a workout) had no effect on product liking $(P>0.05$; results not shown). No significant difference was observed between the number of water or skim milk users within each consumer cluster identified in the HUT $(P>0.05)$. The additional parameters evaluated in the HUT, ease of mixing, drinking, and the mixed well appearance, were correlated with overall liking scores for all consumers and consumer clusters, except ease of mixing for overall liking in $\mathrm{C} 1(P<0.05$; Table 6$)$. These attributes could not be evaluated in a CLT. These results suggest that these specific parameters affect consumer liking of RTM beverages and may warrant further investigation.

For C1 consumers, drivers of liking for RTM beverages were fruity flavor, sweet taste, and viscosity (Figure 5). Drivers of dislike were cardboard flavor and astringency. For C2 consumers, the key driver of liking was viscosity. Drivers of dislike were bitter taste and astringency. Viscosity was a driver of liking for both consumer clusters, and astringency was a driver of dis- 


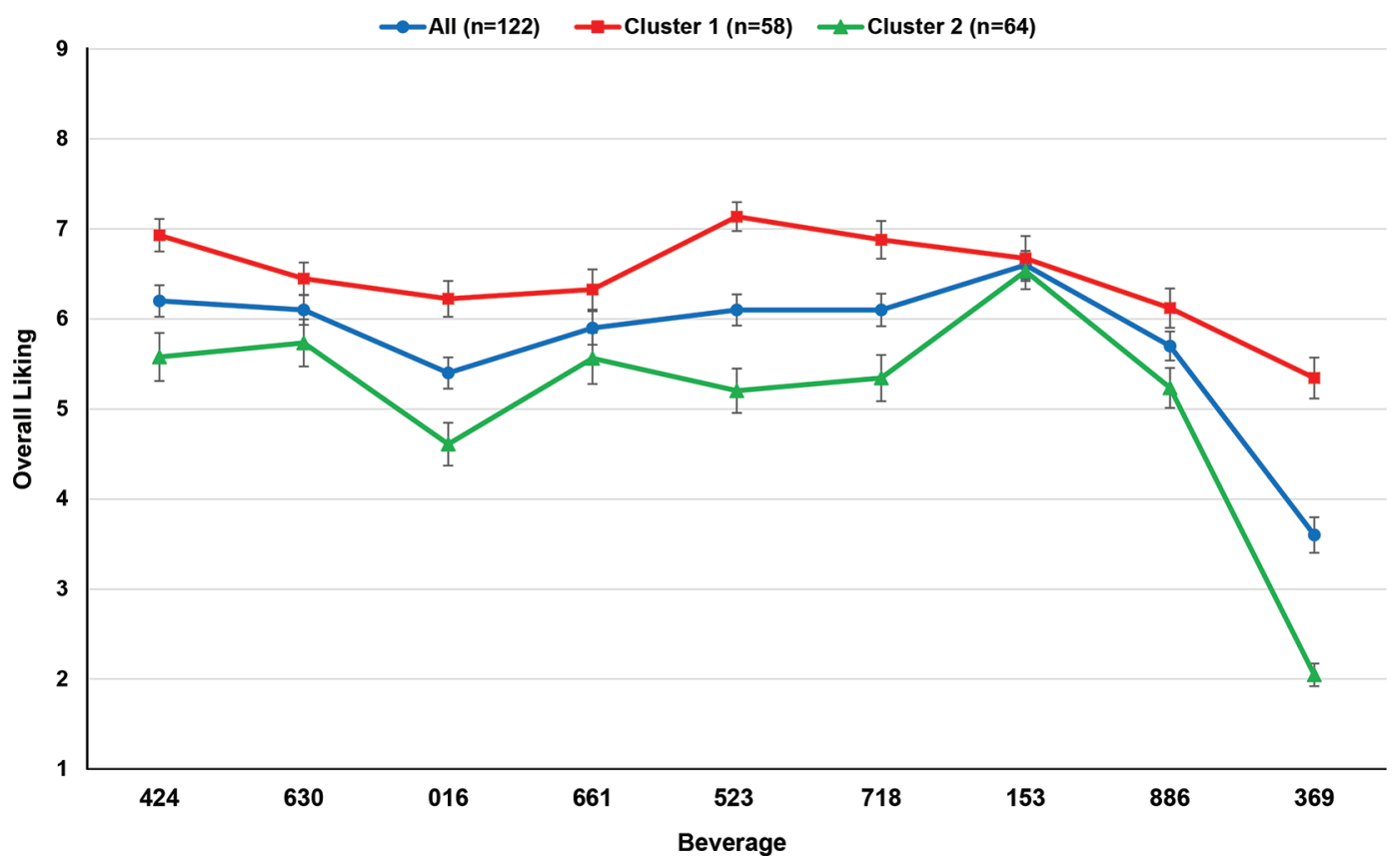

Figure 4. Overall liking scores for rehydrated vanilla-flavored ready-to-mix beverages across all consumers and consumer clusters in the home usage test. Error bars indicate $95 \%$ confidence intervals.

like for both consumer clusters. Consumers from $\mathrm{C} 2$ differed from $\mathrm{C} 1$ by the lack of fruity flavor and sweet taste preferences, the lack of dislike of cardboard flavor, and the additional dislike of bitter taste.

Analysis of check-all-that-apply data revealed that consumers showed more distinct differences among beverages in mouthfeel attributes compared with flavor attributes (Figure 6). The most frequently chosen attributes revealed similar preference trends to external preference mapping (results not shown). For the products that obtained high overall liking scores, consumers frequently described these beverages as buttery, milky, vanilla, sweet taste, and smooth and creamy texture. Burnt, cardboard, and metallic flavors; bitter taste; and chalky, drying, gritty, and powdery textures were frequently checked for products that obtained low overall liking.

\section{Comparison Between CLT and HUT}

In a comparison of CLT and HUT, the overall liking scores from the HUT were higher than those from the CLT (Figure 7). Beverages 016, 661, 523, and 369 obtained higher mean overall liking scores by HUT compared with CLT $(P<0.05$; Table 7 and Figure 7). Both methods showed 2 distinct consumer clusters. Similar drivers of liking and dislike were found between CLT and HUT, but some differences were also present. Both $\mathrm{C} 1$ and $\mathrm{C} 2$ in the CLT and C1 in the HUT had fruity flavor as a driver of liking. Sweet taste was a driver of liking for both C1 in the CLT and C1 in the HUT. Cardboard flavor was a driver of dislike for both consumer clusters in the CLT and C1 in the HUT. Bitter taste was a driver of dislike for both $\mathrm{C} 2$ in the CLT and C2 in the HUT. On the other hand, drivers

Table 5. Mean consumer home usage test overall liking scores from beverages rehydrated with skim milk and water ${ }^{1}$

\begin{tabular}{lccccccccc}
\hline & \multicolumn{9}{c}{ Beverage } \\
\cline { 2 - 9 } Base & 424 & 630 & 016 & 661 & 523 & 718 & 153 & 886 \\
\hline Skim milk $(\mathrm{n}=58)$ & $6.5^{\mathrm{A}, \mathrm{ab}}$ & $6.0^{\mathrm{A}, \mathrm{ab}}$ & $5.9^{\mathrm{A}, \mathrm{b} *}$ & $6.4^{\mathrm{A}, \mathrm{ab} *}$ & $6.0^{\mathrm{A}, \mathrm{ab}}$ & $6.5^{\mathrm{A}, \mathrm{ab} *}$ & $6.6^{\mathrm{A}, \mathrm{a}}$ & $6.0^{\mathrm{A}, \mathrm{ab}}$ & 369 \\
Water $(\mathrm{n}=64)$ & $6.0^{\mathrm{A}, \mathrm{abc}}$ & $6.2^{\mathrm{A}, \mathrm{ab}}$ & $4.9^{\mathrm{B}, \mathrm{d} *}$ & $5.5^{\mathrm{B}, \mathrm{cd} *}$ & $6.3^{\mathrm{A}, \mathrm{ab}}$ & $5.7^{\mathrm{B}, \mathrm{bc} *}$ & $6.6^{\mathrm{A}, \mathrm{a}}$ & $5.4^{\mathrm{A}, \mathrm{cd}}$ & $3.5^{\mathrm{A}, \mathrm{e}}$ \\
\hline
\end{tabular}

$\overline{\mathrm{A}, \mathrm{B}}$ Means with different uppercase superscript letters within a column differ significantly between base liquids for a beverage $(P<0.05)$.

${ }^{\mathrm{a}-\mathrm{e}}$ Means with different lowercase superscript letters within a row differ significantly between beverages within a liquid base $(P<0.05)$.

${ }^{1}$ Liking was scored on a 9 -point hedonic scale where $1=$ dislike extremely and $9=$ like extremely.

*Significant differences in overall liking scores between bases $(P<0.05)$. 
of liking and dislike differed between the CLT and the HUT by buttery flavor, metallic mouthfeel, aftertaste, and astringency. Buttery flavor was a driver of liking exclusively for C2 in the CLT. Metallic and aftertaste were drivers of dislike exclusively for C2 in the CLT. Viscosity was only identified as a driver of liking in the HUT. Astringency was a driver of dislike only in the HUT. Cardboard flavor and bitter taste were the drivers of dislike for consumers in both CLT and HUT, which aligned with previous studies that documented consumer dislike of cardboard flavor in whey protein beverages (Wright et al., 2009; Evans et al., 2010; Oltman et al., 2015).

The CLT identified more drivers of liking and dislike from flavor and taste aspects, whereas the HUT identified more drivers of liking and dislike from a mouthfeel aspect. Astringency perception might be different between the CLT and the HUT due to the larger consumption volume in the HUT. Withers et al. (2014) suggested that a larger consumption volume (200 vs. 40 $\mathrm{mL}$ ) caused a longer lasting duration of astringency perception and perhaps heightened consumer perception of this attribute. A similar difference in volume $(327 \mathrm{~mL}$ for the HUT vs. $60 \mathrm{~mL}$ for the CLT) occurred in the current study. Childs and Drake (2010) addressed that astringency had less impact on acceptance compared with flavors, but again, the study by Childs and Drake (2010) did not evaluate consumer perception following consumption of a typical serving volume. Future work could be conducted to evaluate astringency with consumer acceptance in commercial whey protein beverage products when realistic serving volumes are consumed. The difference between the volumes could also be a factor that affects viscosity perception.

The penalty results from both consumer tests suggest that consumers are looking for vanilla-flavored protein beverages that have strong dairy/milky flavor and low aftertaste. More differences $(P<0.05)$ were observed among beverages by CLT compared with HUT when overall liking was averaged across all consumers. However, similar differentiation of beverages and ranking of liking scores were obtained by either method. More differences $(P<0.05)$ were observed from the CLT than the HUT when comparing the JAR percentages across the beverages for most attributes except texture JAR. On the other hand, more differences $(P<0.05)$ were observed from the HUT than from the CLT when comparing texture JAR percentages across the beverages. In addition, more significant differences $(P<0.05)$ among beverages were observed in overall liking scores among clusters by HUT compared with CLT.

\section{DISCUSSION}

Comparing the overall liking scores between a CLT and a HUT, our results aligned with previous studies that indicated that a CLT resulted in lower liking scores compared with a HUT (Boutrolle et al., 2005; Boutrolle et al., 2007; Sosa et al., 2008; Sveinsdóttir et al., 2010). Although the circumstances are less controlled, a HUT can collect data on more attributes that relate to real-life usage. Previous studies reported that test conditions such as serving size, consumption time in the day, combined consumption with other food items, and social context can affect consumer perception and acceptability of food products (Birch et al., 1984; Hein et al., 2012; Hersleth et al., 2003; King et al., 2004, 2007; Petit and Sieffermann, 2007). Kozlowska et al. (2003) indicated that in a CLT, the evaluation is done in a relatively shorter period of time, whereas the HUT allows the consumers to have a longer exposure time to the product before recording scores, which might cause the products to receive higher acceptance. King et al. (2007) proposed that consumers might need to taste one product after the other, as is the case in CLT but not in HUT, to be able to detect differences if sensory differences are not distinct. Similarly, consumers may be more critical when products are presented and evaluated sequentially, whereas in a HUT, products are evaluated individually with a longer time between samples (a minimum of $22 \mathrm{~h}$ in the current study).

The results from this study showed that beverages in CLT and HUT were discriminated for different aspects. The results from CLT revealed more differences between the beverages in the same consumer cluster and differences between the beverages when evaluating the same attribute. However, compared with the CLT, the results from the HUT showed more significant dif-

Table 6. Home usage test mixing experience correlation significance values, with beverage overall liking

\begin{tabular}{lccc}
\hline Variable & $\begin{array}{c}\text { Ease of } \\
\text { mixing }\end{array}$ & $\begin{array}{c}\text { Appearance } \\
\text { mixed well }\end{array}$ & $\begin{array}{c}\text { Ease of } \\
\text { drinking }\end{array}$ \\
\hline All overall liking & 0.003 & 0.003 & $<0.0001$ \\
Cluster 1 overall liking & 0.124 & 0.029 & 0.001 \\
Cluster 2 overall liking & 0.003 & 0.001 & $<0.0001$ \\
Water user overall liking & 0.009 & 0.01 & $<0.0001$ \\
Milk user overall liking & 0.01 & 0.003 & $<0.0001$ \\
\hline
\end{tabular}


A

Correlations on axes $\mathrm{t} 1$ and $\mathrm{t} 2$

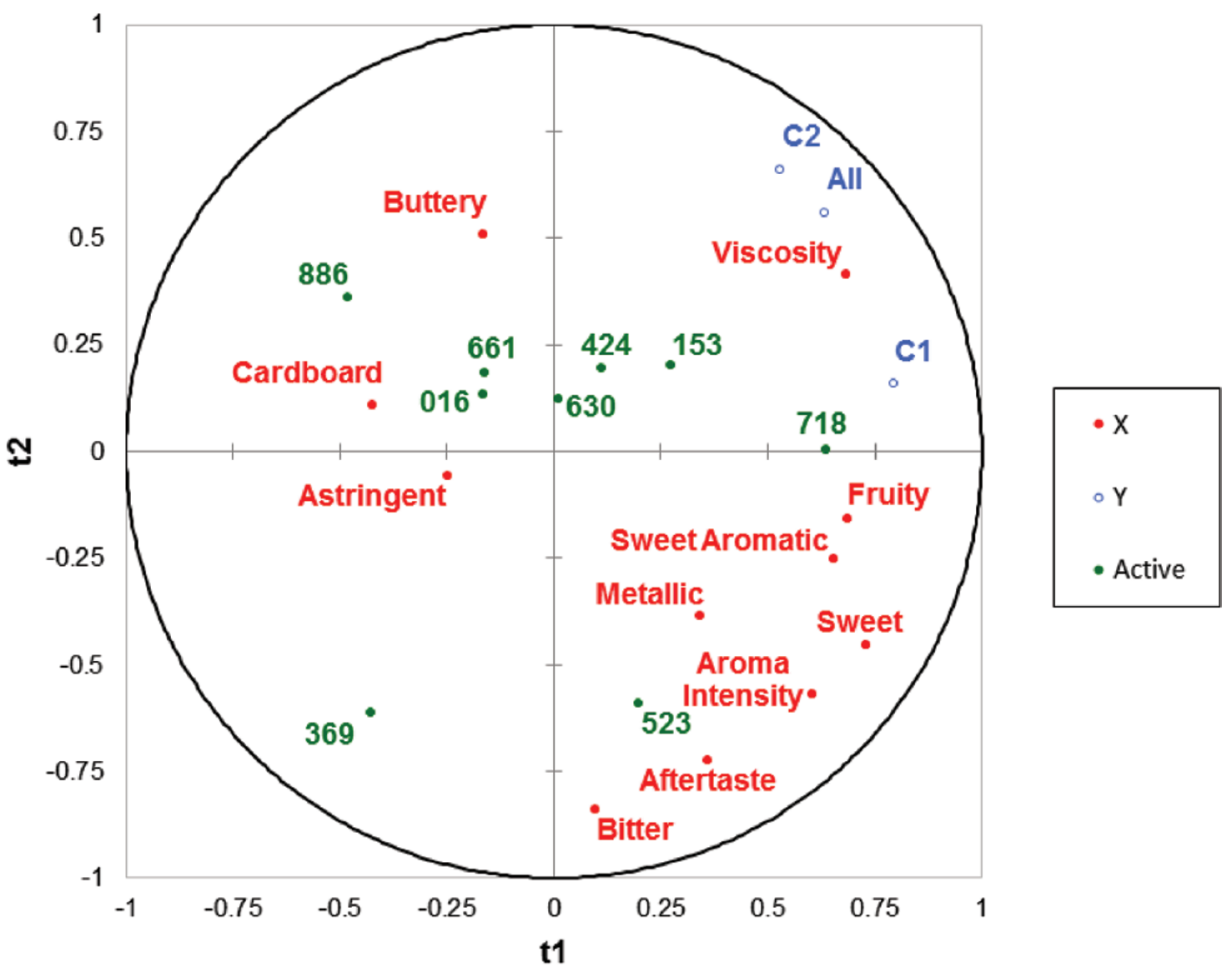

B

Correlations on axes $\mathrm{t} 1$ and $\mathrm{t} 3$

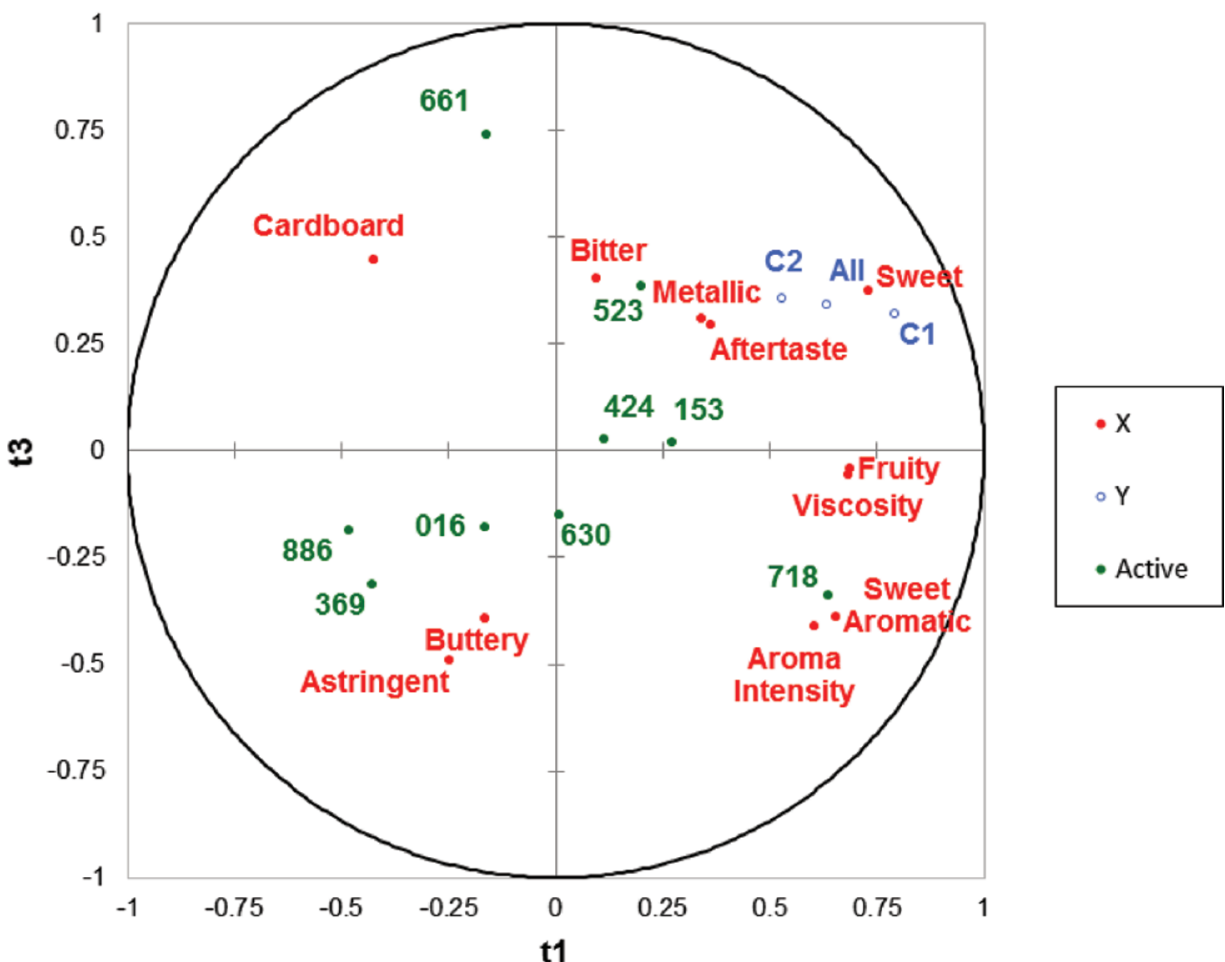

Figure 5. Partial least squares correlation biplot of overall liking scores of clusters $(\mathrm{C} 1=58, \mathrm{C} 2=64)$ for selected rehydrated vanilla-flavored ready-to-mix (RTM) protein beverages in the home usage test; trained panel sensory attributes are identified. Numbers represent RTM samples used for consumer testing. Variance explained as follows: $\mathrm{t} 1=44 \% ; \mathrm{t} 2=26 \%$; $3=12 \%$. 


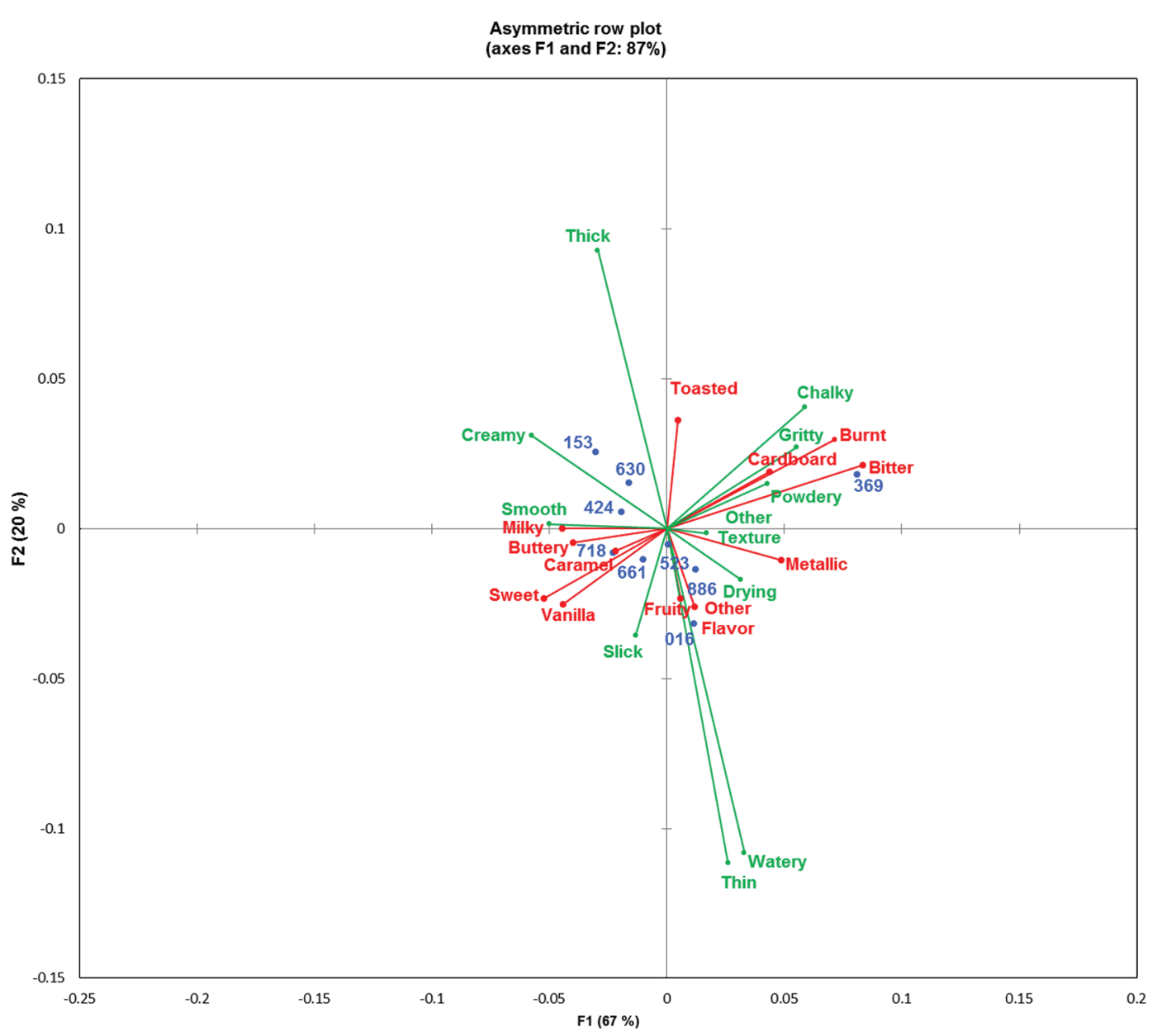

Figure 6. Asymmetric row plot from consumer home usage test check-all-that-apply of vanilla-flavored ready-to-mix (RTM) whey protein beverages. Numbers represent RTM beverages, attributes in red are flavor attributes, and attributes in green are texture attributes.

ferences between consumer clusters when the overall liking scores were compared. In a HUT, factors such as temperature, sample preparation method, and time of consumption cannot be controlled. As such, the overall sensory quality of the product could be affected (Sveinsdóttir et al., 2010), but if the product is not perishable, these variables could make the results closer to real-life consumption experiences. In the case of RTM beverages, this is especially relevant for mixingexperience-related responses, which showed significant correlations to overall liking in this study and are easier to collect in a HUT. The HUT allows consumers to evaluate products in the circumstances that are the same as their daily consumption, and the online questionnaire required consumers to upload photos, which provided a means of making sure instructions were correctly followed.

From both the CLT and the HUT results, ideal vanilla-flavored RTM protein beverages should have vanilla flavors that are characterized by fruity and buttery aromatics with milky/dairy flavor. For the sweetener-specific attributes, lower bitterness and metallic mouthfeel are preferred by consumers. In mouthfeel/ texture, HUT results suggest that consumers prefer beverages that have higher viscosity, which is likely related to the fact that RTM whey protein beverages are promoted as protein "shakes" on the advertising labels. Lower cardboard flavor and astringency, which are whey protein specific off-flavors, are preferred in RTM whey protein beverages. This preference trend is aligned with previous studies with RTD whey protein beverages (Beecher et al., 2006; Wright et al., 2009; Childs and Drake, 2010; Evans et al., 2010; Oltman et al., 2015). Moreover, lower bitter taste, metallic mouthfeel, and aftertaste, which are nonnutritive alternative sweetener specific off-flavors, are also preferred in RTM whey protein beverages. This preference trend is aligned with previous studies with nonnutritive alter- 
Table 7. Comparison of overall liking scores between the central location test (CLT) and the home usage test (HUT) ${ }^{1}$

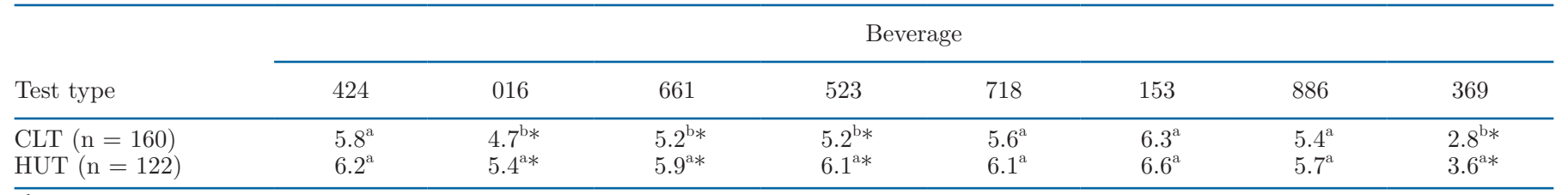

${ }_{\mathrm{a}, \mathrm{b}}$ Means with different letters within a column differ significantly $(P<0.05)$.

${ }^{1}$ Liking was scored on a 9 -point hedonic scale: $1=$ dislike extremely; $9=$ like extremely.

*Significant differences in overall liking scores between CLT and HUT $(P<0.05)$.

native sweeteners (Schiffman et al., 1995; Guggisberg et al., 2011; Li et al., 2015; Parker et al., 2018). For the test method choice between CLT and HUT, based on the specific advantages of these methods, a CLT is useful for differentiating consumer acceptance among vanilla-flavored RTM whey protein beverages based on flavor and taste aspects, whereas a HUT is useful for differentiating the acceptance of the same product between different consumer clusters and determining mouthfeel and mixing experiences. In a CLT, a larger serving volume for collecting mouthfeel-related input might be appropriate if tempered with the ability to evaluate fewer samples in a seating.

\section{CONCLUSIONS}

Both the CLT and the HUT identified fruity flavor and sweet taste as drivers of liking and cardboard fla- vor and bitter taste as drivers of dislike. The HUT also identified viscosity as a common driver of liking and astringency as a common driver of dislike. For the RTM beverage category, a CLT can be used to differentiate consumer acceptance between products and to characterize flavor and taste consumer preferences. Ready-tomix beverages can be evaluated rehydrated in water for the most conservative liking results. Compared with HUT results, a CLT showed consumer preference in a more distinct way, both overall and for individual consumer clusters. This benefit is important for food companies to compare products against competitor brands. However, the HUT confirmed the importance of mouthfeel and key product mixing attributes that cannot be easily evaluated by CLT. These results suggest that a HUT may provide more intensive insights for texture and mouthfeel attributes, likely due to the volumes consumed.

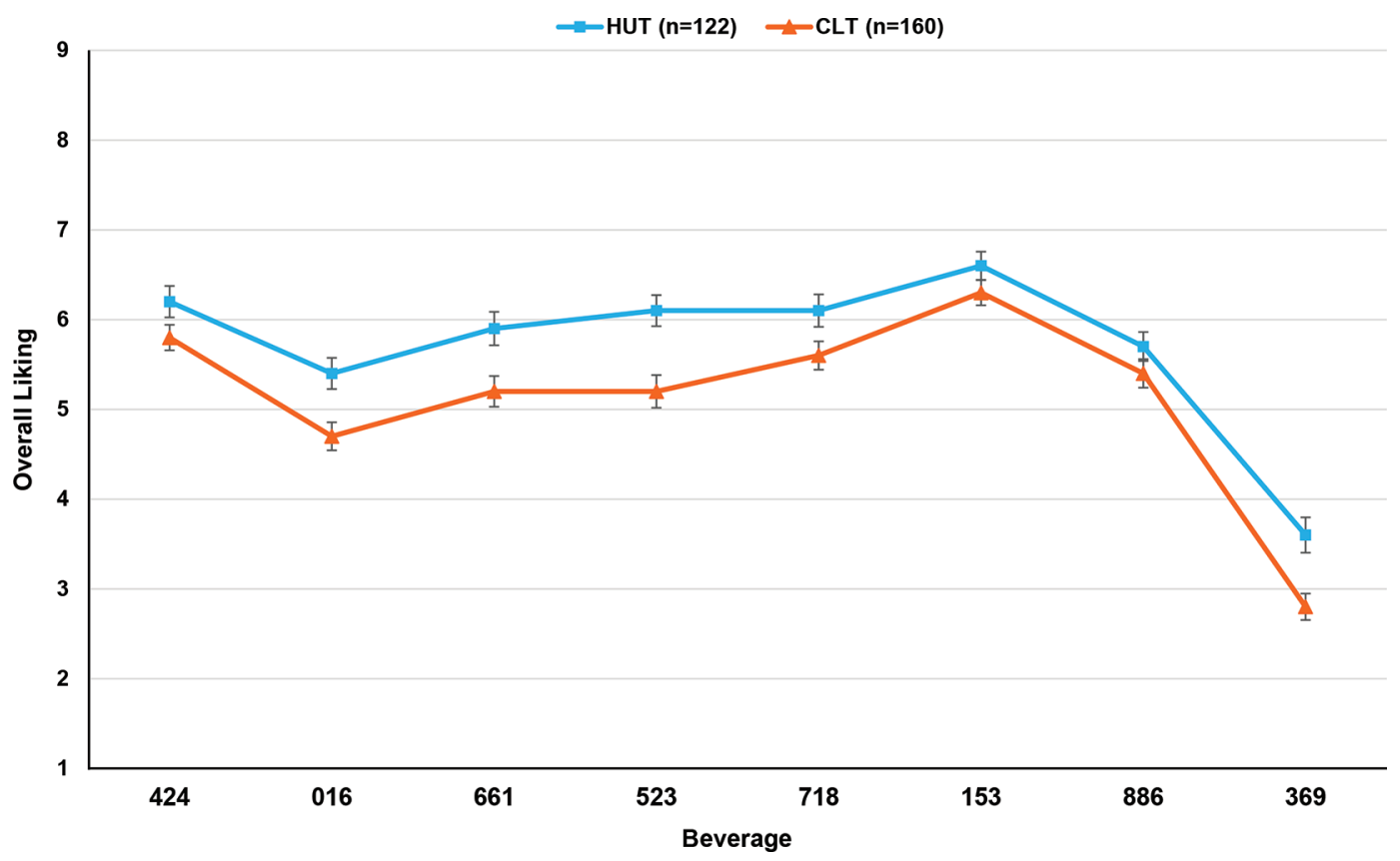

Figure 7. Overall liking scores for rehydrated vanilla-flavored ready-to-mix beverages in the central location test $($ CLT; $\mathrm{n}=160)$ and the home usage test (HUT; $\mathrm{n}=122$ ). Error bars indicate $95 \%$ confidence intervals. 


\section{ACKNOWLEDGMENTS}

Funding was provided in part by Leprino Foods (Denver, CO) and the National Dairy Council (Rosemont, IL). The authors have not stated any conflicts of interest.

\section{REFERENCES}

Beecher, J. W., M. A. Drake, and E. A. Foegeding. 2006. Factors determining flavor and stability of acidic whey protein beverages. Pages 279-291 in The Wonders of Whey. Catch the Power. Proceedings of the 4th International Whey Protein Conference. American Dairy Products Institute, New York, NY.

Birch, L. L., J. Billman, and S. S. Richards. 1984. Time of day influences food acceptability. Appetite 5:109-116. https://doi.org/10 $.1016 /$ S0195-6663(84)80030-6.

Blomstrand, E., and B. Saltin. 2001. BCAA intake affects protein metabolism in muscle after but not during exercise in humans. Am. J. Physiol. Endocrinol. Metab. 281:E365-E374. https://doi.org/10 .1152/ajpendo.2001.281.2.E365

Boutrolle, I., D. Arranz, M. Rogeaux, and J. Delarue. 2005. Comparing central location test and home use test results: Application of a new criterion. Food Qual. Prefer. 16:704-713. https://doi.org/10 .1016/j.foodqual.2005.03.015.

Boutrolle, I., J. Delarue, D. Arranz, M. Rogeaux, and E. P. Koster. 2007. Central location test vs. home use test: Contrasting results depending on product type. Food Qual. Prefer. 18:490-499. https: //doi.org/10.1016/j.foodqual.2006.06.003.

Carunchia Whetstine, M. E., A. E. Croissant, and M. A. Drake. 2005. Characterization of dried whey protein concentrate and isolate flavor. J. Dairy Sci. 88:3826-3839. https://doi.org/10.3168/jds.S0022 $-0302(05) 73068-\mathrm{X}$.

Childs, J. L., and M. A. Drake. 2010. Consumer perception of astringency in clear acidic whey protein beverages. J. Food Sci. 75:S513S521. https://doi.org/10.1111/j.1750-3841.2010.01834.x.

Conner, M. T., and D. A. Booth. 1988. Preferred sweetness of a lime drink and preference for sweet over non-sweet foods, related to sex and reported age and body weight. Appetite 10:25-35. https://doi .org/10.1016/S0195-6663(88)80030-8.

de Graaf, C., A. V. Cardello, F. M. Kramer, L. L. Lesher, H. L. Meiselman, and H. G. Schutz. 2005. A comparison between liking ratings obtained under laboratory and field conditions: The role of choice. Appetite 44:15-22. https://doi.org/10.1016/j.appet.2003.06.002.

Desai, N. T., L. Shepard, and M. A. Drake. 2013. Sensory properties and drivers of liking for Greek yogurts. J. Dairy Sci. 96:7454-7466. https://doi.org/10.3168/jds.2013-6973.

Drake, M. A., and G. V. Civille. 2003. Flavor lexicons. Compr. Rev. Food Sci. Food Saf. 2:33-40. https://doi.org/10.1111/j.1541-4337 .2003.tb00013.x.

Evans, J., J. Zulewska, M. Newbold, M. A. Drake, and D. M. Barbano. 2010. Comparison of composition and sensory properties of $80 \%$ whey protein and milk serum protein concentrates. J. Dairy Sci. 93:1824-1843. https://doi.org/10.3168/jds.2009-2723.

Gerdes, S. 2012. Consumers have a thirst for protein beverages. Dairy Foods 113:22-24.

Gruenwald, J. T. 2009. Fortification of beverages with products other than vitamins and minerals. Pages $92-106$ in Functional and Specialty Beverage Technology. P. Paquin, ed. Woodhead Publishing Limited and CRC Press LLC, Cambridge, UK.

Guggisberg, D., P. Piccinali, and K. Schreier. 2011. Effects of sugar substitution with Stevia, Actilight ${ }^{\mathrm{TM}}$ and Stevia combinations or Palatinose $^{\mathrm{TM}}$ on rheological and sensory characteristics of low-fat and whole milk set yoghurt. Int. Dairy J. 21:636-644. https://doi .org/10.1016/j.idairyj.2011.03.010.

Ha, E., and M. B. Zemel. 2003. Functional properties of whey, whey components, and essential amino acids: Mechanisms underlying health benefits for active people. J. Nutr. Biochem. 14:251-258. https://doi.org/10.1016/S0955-2863(03)00030-5.
Harwood, W. S., and M. A. Drake. 2019. Understanding implicit and explicit consumer desires for protein bars, powders and beverages. J. Sens. Stud. 34:e12493. https://doi.org/10.1111/joss.12493.

Hayes, J. E., and V. B. Duffy. 2008. Oral sensory phenotype identifies level of sugar and fat required for maximal liking. Physiol. Behav. 95:77-87. https://doi.org/10.1016/j.physbeh.2008.04.023.

Hazen, C. 2003. Formulating function into beverages. Accessed Feb. 13, 2020. https://www.naturalproductsinsider.com/specialty -nutrients/formulating-function-beverages.

Hein, K. A., N. Hamid, S. R. Jaeger, and C. M. Delahunty. 2012. Effects of evoked consumption contexts on hedonic ratings: A case study with two fruit beverages. Food Qual. Prefer. 26:35-44. https: //doi.org/10.1016/j.foodqual.2012.02.014.

Hersleth, M., B. H. Mevik, T. Naes, and J. X. Guinard. 2003. Effect of contextual factors on liking for wine-Use of robust design methodology. Food Qual. Prefer. 14:615-622. https://doi.org/10.1016/ S0950-3293(02)00190-8.

Jacobson, J. 2015. Beverage survey finds 'high protein', 'natural' are top trends. Dairy Foods 116:16-17.

King, S. C., H. L. Meiselman, A. W. Hottenstein, T. M. Work, and V. Cronk. 2007. The effects of contextual variables on food acceptability: A confirmatory study. Food Qual. Prefer. 18:58-65. https: //doi.org/10.1016/j.foodqual.2005.07.014.

King, S. C., A. J. Weber, H. L. Meiselman, and N. Lv. 2004. The effect of meal situation, social interaction, physical environment and choice on food acceptability. Food Qual. Prefer. 15:645-653. https: //doi.org/10.1016/j.foodqual.2004.04.010.

Kozlowska, K., M. Jeruszka, I. Matuszewska, W. Roszkowski, N. Barylko-Pikielna, and A. Brzozowska. 2003. Hedonic tests in different locations as predictors of apple juice consumption at home in elderly and young subjects. Food Qual. Prefer. 14:653-661. https://doi.org/10.1016/S0950-3293(02)00207-0.

Lawless, L. J. R., and G. V. Civille. 2013. Developing lexicons: A review. J. Sens. Stud. 28:270-281. https://doi.org/10.1111/joss .12050 .

Li, X. E., K. Lopetcharat, and M. A. Drake. 2015. Parents' and children's acceptance of skim chocolate milks sweetened by monk fruit and stevia leaf extracts. J. Food Sci. 80:S1083-S1092. https://doi .org/10.1111/1750-3841.12835.

Madureira, A. R., C. I. Pereira, A. M. P. Gomes, M. E. Pintado, and F. X. Malcata. 2007. Bovine whey proteins - Overview on their main biological properties. Food Res. Int. 40:1197-1211. https:// doi.org/10.1016/j.foodres.2007.07.005.

Michon, C., M. G. O'Sullivan, C. M. Delahunty, and J. P. Kerry. 2009. The investigation of gender-related sensitivity differences in food perception. J. Sens. Stud. 24:922-937. https://doi.org/10.1111/j $.1745-459$ X.2009.00245.x.

Oltman, A. E., K. Lopetcharat, E. Bastian, and M. A. Drake. 2015. Identifying key attributes for protein beverages. J. Food Sci. 80:S1383-S1390. https://doi.org/10.1111/1750-3841.12877.

Parker, M. N., K. Lopetcharat, and M. A. Drake. 2018. Consumer acceptance of natural sweeteners in protein beverages. J. Dairy Sci. 101:8875-8889. https://doi.org/10.3168/jds.2018-14707.

Petit, C., and J. M. Sieffermann. 2007. Testing consumer preferences for iced-coffee: Does the drinking environment have any influence? Food Qual. Prefer. 18:161-172. https://doi.org/10.1016/j.foodqual 2006.05.008.

Russell, T. A., M. A. Drake, and P. D. Gerard. 2006. Sensory properties of whey and soy proteins. J. Food Sci. 71:S447-S455. https:// doi.org/10.1111/j.1750-3841.2006.00055.x.

Schiffman, S. S., B. J. Booth, M. L. Losee, S. D. Pecore, and Z. S. Warwick. 1995. Bitterness of sweeteners as a function of concentration. Brain Res. Bull. 36:505-513. https://doi.org/10.1016/0361 -9230(94)00225-P.

Schraidt, M. 2009. Appendix L: Penalty analysis or mean drop analysis. Pages 50-53 in Just-About- Right Scales: Design, Usage, Benefits, and Risks. L. Rothman and M. J. Parker, ed. ASTM International, Conshohocken, PA.

Shepard, L., R. E. Miracle, P. Leksrisompong, and M. A. Drake. 2013. Relating sensory and chemical properties of sour cream to con- 
sumer acceptance. J. Dairy Sci. 96:5435-5454. https://doi.org/10 $.3168 /$ jds.2012-6317.

Solak, B. B., and N. Akin. 2012. Health benefits of whey protein: A review. J. Food Sci. Eng. 2:129-137.

Sosa, M., C. Martinez, F. Marquez, and G. Hough. 2008. Location and scale influence on sensory acceptability measurements among lowincome consumers. J. Sens. Stud. 23:707-719. https://doi.org/10 .1111/j.1745-459X.2008.00181.x.

Sveinsdóttir, K., E. Martinsdóttir, F. Thórsdóttir, R. Schelvis, A. Kole, and I. Thórsdóttir. 2010. Evaluation of farmed cod products by a trained sensory panel and consumers in different test settings. J. Sens. Stud. 25:280-293. https://doi.org/10.1111/j.1745 $-459 X .2009 .00257 . x$

Thompson, J. L., M. A. Drake, K. Lopetcharat, and M. D. Yates. 2004. Preference mapping of commercial chocolate milks. J. Food Sci. 69:S406-S413. https://doi.org/10.1111/j.1365-2621.2004 .tb09958.x

Withers, C. A., M. J. Lewis, M. A. Gosney, and L. Methven. 2014. Potential sources of mouth drying in beverages fortified with dairy proteins: A comparison of casein- and whey-rich ingredients. J. Dairy Sci. 97:1233-1247. https://doi.org/10.3168/jds.2013-7273.

Wright, B. J., S. E. Zevchak, J. M. Wright, and M. A. Drake. 2009. The impact of agglomeration and storage on flavor and flavor stability of whey protein concentrate $80 \%$ and whey protein isolate. J. Food Sci. 74:S17-S29. https://doi.org/10.1111/j.1750-3841.2008 .00975 .x

Young, N. D., M. A. Drake, K. Lopetcharat, and M. R. McDaniel. 2004. Preference mapping of Cheddar cheese with varying maturity levels. J. Dairy Sci. 87:11-19. https://doi.org/10.3168/jds .S0022-0302(04)73136-7.

\section{ORCIDS}

M. A. Drake ㄴ https://orcid.org/0000-0002-4744-2493 